\title{
Circular zero-residue process using microalgae for efficient water decon- tamination, biofuel production, and carbon dioxide fixation
}

\author{
Albert Serrà, ${ }^{* 1}$ Raul Artal, ${ }^{2}$ Jaume García-Amorós, ${ }^{3,4}$ Elvira Gómez, ${ }^{2,4}$ and Laetitia Philippe ${ }^{1}$ \\ ${ }^{1}$ Empa, Swiss Federal Laboratories for Materials Science and Technology, Laboratory for Mechanics \\ of Materials and Nanostructures, Feuerwerkerstrasse 39, CH-3602 Thun, Switzerland. \\ ${ }^{2}$ Grup d'Electrodeposició de Capes Primes i Nanoestructures (GE-CPN), Departament de Ciència de \\ Materials i Química Física, Universitat de Barcelona, Martí i Franquès, 1, E-08028, Barcelona, Catalo- \\ nia, Spain.
}

${ }^{3}$ Grup de Materials Orgànics, Departament de Química Inorgànica i Orgànica (Secció de Química Orgànica), Universitat de Barcelona, Martí i Franquès, 1, E-08028, Barcelona, Catalonia, Spain.

${ }^{4}$ Institute of Nanoscience and Nanotechnology (IN $\left.{ }^{2} \mathrm{UB}\right)$, Universitat de Barcelona, Barcelona, Catalonia, Spain.

*Corresponding author. E-mail: albert.serraramos@empa.ch

\begin{abstract}
Microalgae can be easily integrated into an effective and scalable zero-carbon-emission circular process that exploits their $\mathrm{CO}_{2}$ fixation and wastewater remediation capabilities while simultaneously using their residues as an energy and biofuel source to power global sustainable development. Herein, the use of glycogen-rich Arthrospira platensis microalgae for efficient water decontamination, biofuel production, and $\mathrm{CO}_{2}$ fixation is explored. The circular process is initiated by efficient bioremediation of heavy metals (removal $>99 \%$ ) during microalgal growth, followed by bioethanol production, pellet production, and mineralization of persistent organic pollutants from wastewater, and is accompanied by $\mathrm{CO}_{2}$ fixation and/or oxygen production. Microalgal biomass generated during heavy metal bioremediation is used to
\end{abstract}


produce bioethanol via simultaneous saccharification and fermentation $(0.4 \mathrm{~L}$ per $\mathrm{kg}$ of dried microalgal biomass). The residual biomass obtained after bioethanol production is dried and compressed into pellets for its use as a fuel in biomass boilers (calorific power $=20.6 \pm 0.2 \mathrm{MJ} \mathrm{kg}^{-1}$ ). The iron-rich ashes produced during pellet combustion are subsequently used as heterogeneous re-usable Fenton-like catalysts for the photo-Fenton degradation (mineralization $>99 \%$ ) of persistent organic pollutants. Finally, the low-activity ashes are incorporated into an ash-based medium for the efficient cultivation of microalgae. For each proposed step, product characterization and evaluation were conducted to optimize and enhance the process performance while minimizing negative effects on the environment.

\section{Graphical Abstract}

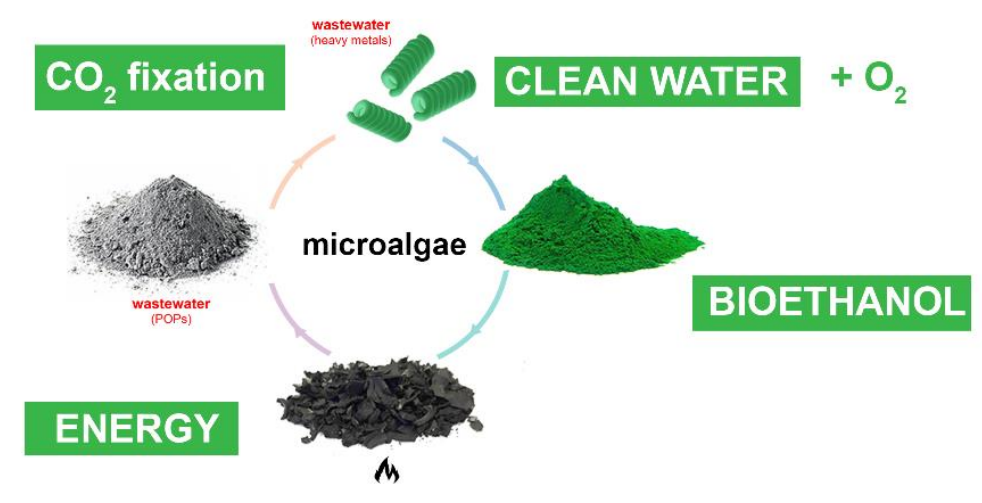

\section{Highlights}

- A circular process for water decontamination, biofuel production and $\mathrm{CO}_{2}$ fixation is proposed.

- Microalgae show heavy metal bioremediation in a wide $\mathrm{pH}$ range.

- Saccharification and fermentation of rich-heavy metal Spirulina lead to bioethanol.

- Iron-rich ashes are useful catalysts in photo-Fenton POPs mineralization.

- $\quad$ Pelletization of biomass residues provides effective solid biofuel.

Keywords: circular chemistry; microalgae; water decontamination; bioethanol production; pellets 


\section{Introduction}

Microalgae are photosynthetic microorganisms with potential applications in renewable energy, water/air decontamination, and biopharmaceutical/cosmetic/nutraceutical industries, making their utilization important for developing new business models and integrating green and sustainable chemistry within a circular economy [1-5]. Microalgae offer an inexpensive opportunity to power global sustainable development as they are typically found in lakes, rivers, and oceans, but are capable of rapid growth in a variety of environments, being tolerant of broad ranges of salinity, $\mathrm{pH}$, and temperature. This tolerance allows for microalgae cultivation in conditions that are unsuitable for traditional agricultural activities or directly in seas or oceans. Furthermore, the cultivation of microalgae can also make use of water that is unsuitable for human consumption or agriculture [6-8]. Therefore, microalgal cultivation does not compete with or affect traditional agriculture. Given the relatively low cost of startup for microalgal production and the fact that microalgal cultivation and posterior usage are scalable, sustainable, applicable, and suitable for developing countries, the microalgal industry can be viewed as a global job creation engine [6-8].

Microalgae can metabolize nutrients and other inorganic/organic compounds from wastewater and are well suited for the bioaccumulation and biosorption of organic compounds, which are then metabolized [9-11]. Additionally, microalgae have the capability to absorb heavy metals (e.g., $\mathrm{Cr}, \mathrm{Pb}, \mathrm{Fe}$, and $\mathrm{Co}$ ions or metallic nanostructures) [12-15]. This exceptional capacity of microalgae to remove organic compounds and heavy metals, two critical wastewater pollutants, can be used for water decontamination. Since the biochemical composition (micronutrient, protein, carbohydrate, and lipid contents) of the microalgal skeleton depends on the cultivation conditions, microalgae can be used to produce biofuels, animal feeds, dietary supplements, cosmetics, bioplastics, fertilizers, lubricants, drugs, etc $[5,16]$. The production of biofuels such as biodiesel and bioethanol is one of the most promising applications given the high biofuel yields achieved, offering a renewable energy source with a minimal contribution to environmental pollution and global warming [5, 17-19].

Many researchers have investigated the optimization of individual microalgae-based processes such as lipid extraction or algal biomass fermentation for bioethanol production [17-21]. The development of 
linear-route production processes, in which microalgal resources are consumed and wastes are generated, offers environmentally friendly alternatives to several global problems such as climate change, energy crisis or resource depletion. Still, the incorporation of circular chemistry principles to mimic the microalgal life cycle and convert wastes into new sources for other processes is necessary for total sustainability [2]. Therefore, circular thinking can reinvent business and industrial production models by integrating various processes into a single holistic, simple, green, and sustainable process with zero or quasi-zero residue production.

Figure 1 shows the proposed circular process for water decontamination and bioethanol and energy production based on the use of Arthrospira platensis microalgae, commonly known as Spirulina. The proposed circular process is replicable, simple, easily scalable, green, sustainable, and low-cost. Consequently, it is highly implementable in developing countries in terms of renewability, sustainability, and economic feasibility. The developed process features five successive stages:

1. Microalgae are cultivated using sunlight and wastewater in the presence of iron ions and wastes (i.e., iron-rich ashes) produced during the circular process, which allows the fixation of carbon dioxide and biosorption of (in)organic compounds. The excellent capability of Spirulina to undergo biosorption of iron ions and other (in)organic compounds; allows for the simultaneous production of clean water and oxygen in this stage.

2. The glycogen-rich microalgal biomass generated in the culture medium is used to produce bioethanol through simultaneous saccharification and fermentation. In this step, residual biomass and bioethanol are obtained, and carbon dioxide is released.

3. After glycogen extraction, the microalgal biomass is dried, pelletized, and used as a fuel that can be burned for power generation. Consequently, residual microalgal biomass is used to generate power with the simultaneous production of carbon dioxide and ashes.

4. The iron-rich ashes produced during combustion are used for the photo-Fenton mineralization of persistent organic pollutants (e.g., methylene blue) promoted by sunlight. During this process, carbon dioxide is released, while organic compounds are photodegraded.

5. To close the cycle, mineralized water obtained after the photo-Fenton process is reused to cultivate more microalgae. 
This holistic process generates clean water, bioethanol, and energy while fixating carbon dioxide and releasing oxygen. The generated residues are recycled and eliminated to realize an efficient life cycle, introducing a zero-residue process based on sustainable use of resources.

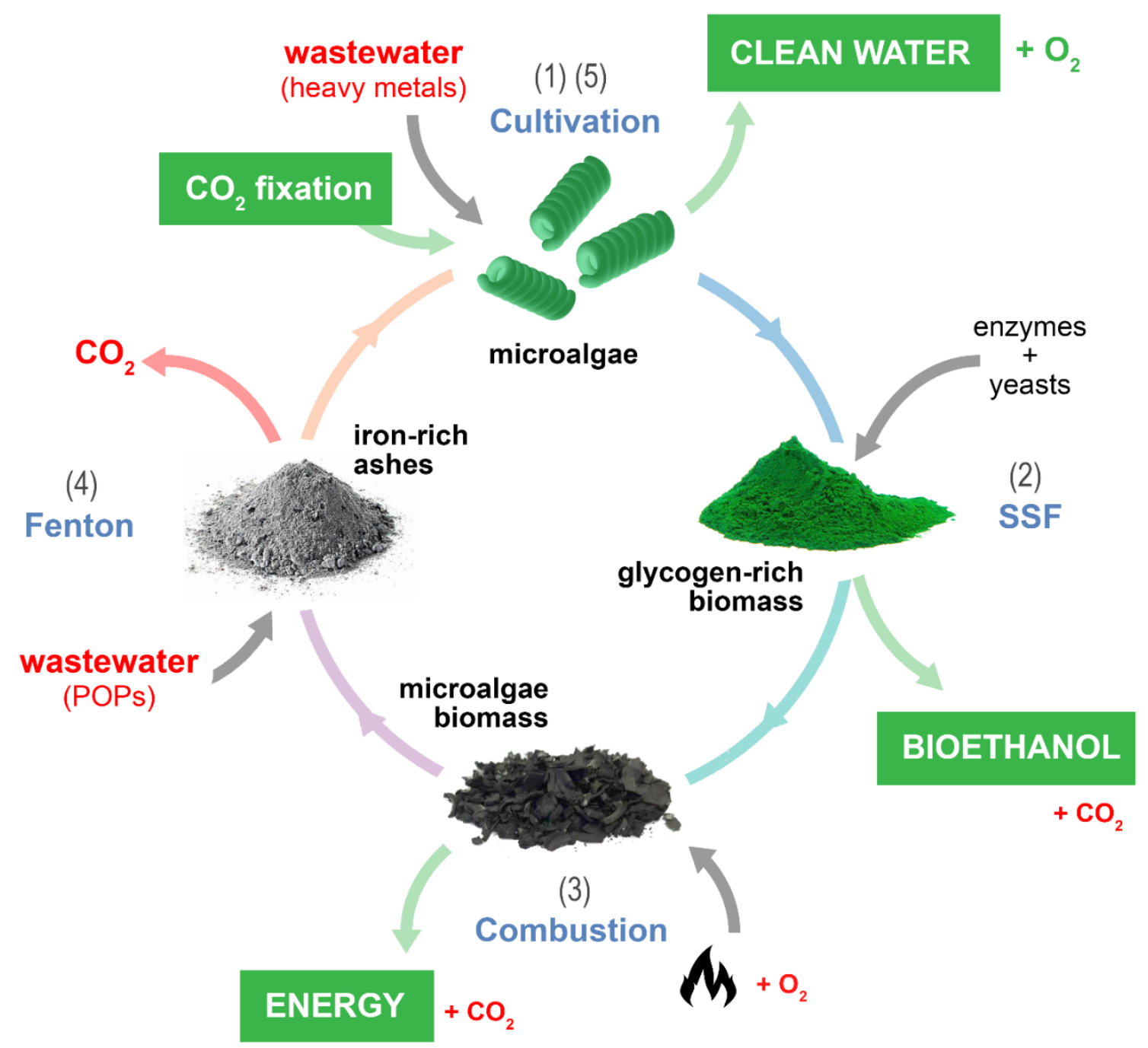

Figure 1: Schematic illustration of the circular process using Spirulina microalgae for water decontamination and production of bioethanol and energy through five successive stages: (1) the microalgae cultivation for carbon dioxide fixation and simultaneous production of clean water and oxygen; (2) simultaneous saccharification and fermentation of glycogen-rich microalgal biomass to produce bioethanol; (3) pelletization and combustion of microalgal residues to obtain thermal energy; (4) photo-Fenton mineralization of persistent organic pollutants using microalgal ashes (solid residue) produced during the combustion of microalgal pellets; and (5) reuse of mineralized water, containing microalgal ashes to cultivate more microalgae, closing the circular process. 


\section{Experimental}

\subsection{Microalgae cultivation and characterization}

Microalgae cultivation: The microalgae A. platensis var lonar obtained from Espirulina Natural Company (Catalonia) were cultivated in two 30 L glass tank using either a nitrate-deficient Zarrouk's medium with $4 \mathrm{mM}$ of $\mathrm{NaNO}_{3}$ or a homemade ash-based medium that was 30\% (v/v) Zarrouk's medium and $70 \%(\mathrm{v} / \mathrm{v})$ recycled iron-rich microalgae ash solution (i.e., $1 \mathrm{~g}$ of ash per $\mathrm{L}$ of decontaminated wastewater; the elemental composition of the iron-rich microalgae ash is summarized in Table S1). During cultivation, the cultivation tank was set at $29.5 \pm 0.4^{\circ} \mathrm{C}$ and subjected to intermittent mechanical agitation at $80 \mathrm{rpm}$ in two 30- and 15-min on-off cycles, followed by air bubbling in two 15- and 60min on-off cycles. The cultivation was performed under natural sunlight irradiation with an average light intensity of 1,350 $\pm 4501 \mathrm{x}$. The $\mathrm{pH}$ was controlled daily and maintained at a value of 10 . Commercial A. platensis paracas powder, obtained from SF Superfoods (Australia), was used as a reference.

Biomass determination: Three $20-\mathrm{mL}$ samples of each microalgae cultivation tank were extracted and filtered through pre-weighed Whatman glass microfiber filters (WHA1825021, Sigma-Aldrich) daily for $8 \mathrm{~d}$ to estimate the microalgae biomass. Filters containing the biomass were kept in an oven at $40^{\circ} \mathrm{C}$, dried, and weighed. Biomass production was calculated as $\mathrm{mg} \mathrm{L}^{-1}$.

Photosynthetic pigments determination: The concentration of chlorophyll-a and carotenoids' concentration in microalgae was spectroscopically measured using Lichtenthaler and Wellburn method [22-24]. Three 5-mL samples from each microalgae cultivation tank were centrifuged at 5,000 rpm for $10 \mathrm{~min}$ and later washed with phosphate-buffered saline (PBS) solution 3 times. Once the supernatant was discarded, ethanol (96\% v/v) was thoroughly mixed in to the microalgae residues, after which the pigments were extracted in ethanol at $65{ }^{\circ} \mathrm{C}$ for $90 \mathrm{~min}$. The absorbance of the supernatant in the ethanol solution at 470, 649, and $665 \mathrm{~nm}$ was measured using a UV-1800 Shimadzu UV-vis spectrophotometer (Shimadzu Corporation). The concentration of chlorophyll-a and carotenoids was calculated according to Lichtenthaler and Wellburn equation's [22-24]. 
Glucose and glycogen determination: Glucose and glycogen were mechanically extracted from both commercial and cultivated Spirulina in cold PBS (i.e., $0.01 \mathrm{M}$ of phosphate buffer, $0.0027 \mathrm{M}$ of KCl, and $0.137 \mathrm{M}$ of $\mathrm{NaCl}, \mathrm{pH} 7.4$ ) using a laboratory homogenizer at 20,000 rpm for $3 \mathrm{~min}$. Several brief 30-s on-off cycles of mechanical extraction were performed while the sample was immersed in an ice bath. Glucose and glycogen contents were determined using a glucose assay kit (\#GAGO20, SigmaAldrich) and a glycogen assay kit (\#MAK016, Sigma-Aldrich), respectively, in analysis performed in triplicate.

Iron determination: To determine iron content, $0.2 \mathrm{~g}$ (dry weight) of commercial and cultivated Spirulina were digested in $8 \mathrm{~mL}$ of nitric acid in closed Teflon vessels using the microwave sample digestion system Mars $6^{\mathrm{TM}}(\mathrm{CEM})$. After digestion, the solution was diluted to a final volume of $20 \mathrm{~mL}$ with MilliQ water, and total iron content was determined using inductively coupled plasma atomic emission spectroscopy with a Optima 3200RL model ICP-AES (PerkinElmer). Each analysis was performed in triplicate.

\subsection{Heavy metal bioremediation}

For experiments with the heavy metal bioremediation, $0.4 \mathrm{~g}$ (dry weight) of commercial and ash-cultivated Spirulina were resuspended in both a single-pollutant laboratory sample, based on a 40-ppm iron(II) chloride (>99.0\%, Sigma-Aldrich) solution prepared with Milli-Q water, and real wastewater from the main drain of a local electroplating industry. Once the real effluent was filtered and diluted to a final concentration of $\mathrm{Cu}(\mathrm{II})$ of $80 \mathrm{mg} \mathrm{L}^{-1}, \mathrm{Cu}$ (II) was found to be the primary pollutant in the effluent water. The $\mathrm{pH}$ was adjusted to the desired value using $0.1 \mathrm{M}$ of $\mathrm{NaOH}$ or $\mathrm{HCl}$ prior to resuspending the microalgae biomass. The bioremediation of heavy metals was performed in triplicate at $25.1 \pm 0.1^{\circ} \mathrm{C}$ for 90 min under magnetic stirring at $200 \mathrm{rpm}$. Iron, copper, nickel, zinc and chromium contents were determined using inductively coupled plasma atomic emission spectroscopy with the same Optima 3200RL model ICP-AES. Prior to conducting the heavy metal bioremediation experiments, the functional groups of the microalgae biomass were determined using fast-Fourier infrared spectra with a Spectrum 2 IR (PerkinElmer). 


\subsection{Bioethanol production}

A simultaneous saccharification and fermentation (SFF) process was used for the bioethanol production from commercial and ash-cultivated Spirulina. The following procedure was used for bioethanol production:

- Glycogen and glucose were mechanically extracted in $100 \mathrm{~mL}$ of YEP fermentation media (Formedium ${ }^{\mathrm{TM}}$ ) $-10 \mathrm{~g} \mathrm{~L}^{-1}$ of yeast extract $+20 \mathrm{~g} \mathrm{~L}^{-1}$ of Peptone - by using a laboratory homogenizer (20,000 rpm, $3 \mathrm{~min})$. Multiple short on-off cycles (30s) were conducted while the sample was immersed in an ice bath. Bioethanol production was performed with the non-filtered medium using only supernatants. Supernatants were recovered through $0.2 \mu \mathrm{m}$ syringe filters.

- At the same time, Ethanol Red ${ }^{\mathrm{R}}$ (hybrid yeast) provided by Société Industrielle Lesaffre, Division Leaf (France), was prepared. Yeasts were prepared using the following procedure: (i) yeasts were first rehydrated for $30 \mathrm{~min}$ in five times their weight of sterile water at $31^{\circ} \mathrm{C}$, and then (ii) the hydrated yeasts were grown in YPD medium (Formedium ${ }^{\mathrm{TM}}$ ) $-10 \mathrm{~g} \mathrm{~L}^{-1}$ of yeast extract $+20 \mathrm{~g} \mathrm{~L}^{-1}$ of Peptone $+20 \mathrm{~g} \mathrm{~L}^{-1}$ of Glucose-at $31^{\circ} \mathrm{C}$ under $\mathrm{CO}_{2}$ bubbling for $30 \mathrm{~h}$, collected by centrifugation $(10,000 \mathrm{rpm})$ for $3 \mathrm{~min}$ at $25^{\circ} \mathrm{C}$, and washed twice with distilled water. The yeast concentration was controlled and stablished using a Neubauer chamber.

- The supernatants from glycogen and glucose extraction $(100 \mathrm{~mL})$ were mixed with $100 \mathrm{~mL}$ of saccharification media prepared using YEP fermentation medium to obtain a $1.5 \mathrm{U} \mathrm{L}^{-1} \alpha$-Glucosidase from Saccharomyces cerevisiae (\#G5003, Sigma-Aldrich) and $3.5 \mathrm{U} \mathrm{L}^{-1} \alpha$-Amylase from porcine pancreas (\#A3176, Sigma-Aldrich) concentration. Simultaneously, yeasts were introduced to obtain an initial concentration of $\sim 1.5510^{7}$ yeast $\mathrm{mL}^{-1}$ of Ethanol $\operatorname{Red}^{\mathrm{R}}$.

- $\quad$ Next, the SFF process commenced. The SFF process was conducted under magnetic stirring (300 $\mathrm{rpm})$ at $31 \pm 0.3^{\circ} \mathrm{C}$. The time-dependent evolution of ethanol content was determined during the 26 h period of each experiment using a GC-2010 gas chromatograph (Shimadzu) equipped with a flame ionization detector and a HP-5 column $(30 \mathrm{~m} \times 0.32 \mathrm{~mm}$ of internal diameter, $0.25 \mu \mathrm{m}$ of film thickness). 


\subsection{Pelletization, combustion experiments and ash characterization}

A single pelletizer machine was used to produce well-defined single cylindrical pellets. The equipment is composed by a cylinder of $6 \mathrm{~mm}$ of internal diameter and $10 \mathrm{~cm}$ in length and a piston of $6 \mathrm{~mm}$ in diameter and $12.5 \mathrm{~cm}$ in length, both placed under the crosshead of a mechanical testing machine. Temperature and force can be measured and controlled during the pelletizing process. The following procedure was used to produce microalgae pellets: (i) microalgae were dried at room temperature to attain a humidity of approximately of $10-15 \%\left(\mathrm{w} / \mathrm{w}\right.$ ); (ii) the cylinder was pre-heated to $55^{\circ} \mathrm{C}$ prior to introduce the microalgae biomass; (iii) the pre-heated cylinder was loaded with microalgae biomass until it was full; (iv) microalgae was compressed at a maximum force of $3500 \mathrm{~N}$ during $90 \mathrm{~s}$; and (v) finally, the pellet was removed from the cylinder by moving the crosshead downward. The fabricated pellet was cooled at room temperature.

Based on the standard UNE-EN ISO 18134-2, humidity content of microalgae pellets was carried out by a balance (accuracy $\pm 0.0001 \mathrm{~g}$ ) and an oven at $105^{\circ} \mathrm{C}$. Ashes were obtained after the microalgae pellet combustion in a Heraeus M110 Muffel oven (constant temperature of $1000^{\circ} \mathrm{C}$ ). Calorific power was determined using an IKA ${ }^{\circledR}$ calorimeter C 5000. Finally, thermogravimetric analysis in an inert (nitrogen) and oxidizing (air) atmosphere were performed from room temperature to $1000^{\circ} \mathrm{C}$ using a Mettler TGA/SDTA851 ${ }^{\mathrm{e}}$ thermobalance (gas flux: $50 \mathrm{~mL} \mathrm{~min}^{-1}$; heat rate: $10{ }^{\circ} \mathrm{C} \mathrm{min}{ }^{-1}$ ).

The obtained microalgae ashes were morphologically characterized using a field emission scanning electron microscopy (FE-SEM, Hitachi S-4800) equipped with an energy-dispersive x-ray spectroscopy detector. The specific surface area of each biomimetic photocatalyst was determined based on the Brunauer-Emmett-Teller (BET) method from $\mathrm{N}_{2}$ adsorption-desorption isotherms at $77 \mathrm{~K}$ using a Micrometrics Tristar-II. Ash elemental composition was carried out by X-ray photoelectron spectroscopy (XPS) at room temperature with a SPECS PHOIBOS 150 hemispherical analyzer (SPECS GmbH).

\subsection{Fenton and photo-Fenton experiments}


Fenton-like catalysts $\left(\mathrm{FeCl}_{2}\right.$ (Sigma-Aldrich, $98 \%$ ) or iron-rich ashes) were added to $100 \mathrm{~mL}$ beakers containing a $10 \mathrm{ppm}$ methylene blue (MB) (Sigma-Aldrich, > 97\%) polluted solution. The solution $\mathrm{pH}$ was then adjusted to the desired value $(\mathrm{pH}=3)$ using a dilute sulfuric acid. Next, the Fenton or photoFenton process was initiated by adding $\mathrm{H}_{2} \mathrm{O}_{2}$. The initial content of MB, Fenton-like catalyst and $\mathrm{H}_{2} \mathrm{O}_{2}$ were $10 \mathrm{ppm}, 0.1 \mathrm{~g} \mathrm{~L}^{-1}$, and $10 \mathrm{mM}$, respectively. All the experiments were thermostated at $20.1 \pm 0.2^{\circ} \mathrm{C}$ and maintained under magnetic stirring (400 rpm). In order to evaluate the adsorption effect, the experiments were also done when the catalyst was kept with the pollutant solution for 30 min prior to adding $\mathrm{H}_{2} \mathrm{O}_{2}$. For photo-Fenton experiments, an $8 \mathrm{~W}$ mercury lamp setup with the wavelength of $365 \mathrm{~nm}$ (light intensity of $1.4 \mathrm{~W} \mathrm{~m}^{-2}$ ) or natural sunlight (average light intensity $1.6 \mathrm{~W} \mathrm{~m}^{-2}$ ) were used. Iron-rich ashes were collected and reused to during five consecutive cycles for the degradation of $10 \mathrm{ppm} \mathrm{MB} \mathrm{-} \mathrm{only}$ under UV irradiation - to evaluate the stability, recyclability and reusability properties.

The MB degradation was tracked by UV-vis spectroscopy (UV-1800 spectrophotometer, Shimadzu) in a quartz cuvette with an optical length of $1 \mathrm{~cm}$. Degradation efficiency was determined from the temporal evolution of the reduction in peak intensity at $\lambda_{\mathrm{m}}=662 \mathrm{~nm}$ during a 100 -min period of reaction. The mineralization of MB solutions was monitored from the abatement of their total organic carbon (TOC) after 100-min period of reaction, determined on a Shimadzu $\mathrm{V}_{\mathrm{CSH}}$ analyzer.

\section{Results and Discussion}

The cyanobacteria A. platensis was selected among photosynthetic microorganisms due to its extended cultivation throughout the world and its versatility that allows for potential applications in numerous fields, including the nutritional, nutraceutical, pharmaceutical and energy industries [7, 17, 25]. There are other types of bacteria and other photosynthetic microorganisms that are also effective for heavy metal biosorption (e.g., Cupriavidus metallidurans) or bioethanol production (e.g., Chlamydomonas) $[26,27]$. Consequently, the proposed effective and scalable zero-carbon-emission circular process can be extended to other algal biomass. A. platensis is an ideal candidate for integration in a self-sustainable circular process due to its effectiveness in water decontamination, carbon dioxide fixation, oxygen production, and biofuel production. Although the nutritional and nutraceutical applications of A. platensis 
cultivation are not considered in this work, the extraction of pigments, lipids, or proteins can be easily achieved before the formation of microalgal pellets.

\subsection{Microalgal cultivation - Beginning the circular process}

Biomass production and the biochemical composition of microalgae can easily be tuned using nutrimental strategies such as varying the culture media composition (i.e., medium salinity, nitrogen and

phosphorous limitations or changes in carbon sources) or by physical strategies (e.g., light intensity, irradiation dose). It is known that the cultivation of microalgae in nitrate-deficient media negatively affects biomass production but significantly enhances the production of energy-rich components like lipids and carbohydrates, as well as accessory pigments like carotenoids. This approach also reduces the yield of nitrogen-rich components such as proteins and chlorophyll [28-30].

Consequently, the selection of a proper microalgal culture medium is key to ensuring the viable industrial cultivation of Spirulina, since it determines the biochemical composition of the microalgal biomass, which strongly influences the subsequent bioethanol production and biomass yield [10, 15]. Among the unconventional culture media used to avoid high production costs, those based on vegetal ashes (e.g., cow dung ash) or wastewater are notable for their low cost and high performance $[6,31,32]$.

Herein, A. platensis var lonar was cultivated in an ash-based medium comprising 30 vol. \% Zarrouk's medium and 70 vol. \% iron-rich recycled microalgae ash solution $(1 \mathrm{~g}$ of ash per $\mathrm{L}$ of decontaminated wastewater). Table S1 summarizes the physicochemical composition of the microalgal iron-rich ashes and the total organic content of the decontaminated water after photo-Fenton mineralization (see the photo-Fenton water decontamination section for details).

As shown in Figure 2a and $\mathbf{b}$ and Table S2, no marked differences were observed between the nitratedeficient Zarrouk's medium ( $4 \mathrm{mM} \mathrm{NaNO}_{3}$ ) and the ash-based medium in terms of biomass production and glycogen content of cultivated A. platensis. The glycogen content of the microalgae in nitrate-deficient Zarrouk's medium and the ash-based medium were approximately $70 \mathrm{wt} \%$ of the dry biomass, 
whereas those of commercial A. platensis and ash-based A. platensis cultured in $30 \mathrm{mM} \mathrm{NaNO}$ Zarrouk's medium were only 7 and $21 \mathrm{wt} . \%$, respectively. In addition, the content of photosynthetic pigments (chlorophyll and carotenoids) was similar between the nitrate-deficient Zarrouk's medium and the ash-based medium, where the content of chlorophyll was approximately $3.5 \mathrm{wt} . \%$ and the content of carotenoids was approximately 0.4 wt. \%. The chlorophyll and carotenoid contents of A. platensis cultured in non-nitrate deficient medium were approximately $8 \mathrm{wt} . \%$ and $<0.08 \mathrm{wt} . \%$, respectively. Therefore, the biomass production was relatively low compared with production resulting from cultivation in other media, but the biochemical composition was adequate for the effective production of bioethanol.

Consequently, the recycling of the iron-rich ashes used for the photo-mineralization of persistent organic pollutants allowed for the preparation of an economical, efficient, green, and sustainable microalgal culture medium and enabled a zero-residue process. As additional benefits, carbon dioxide is fixated and oxygen is released. 
a

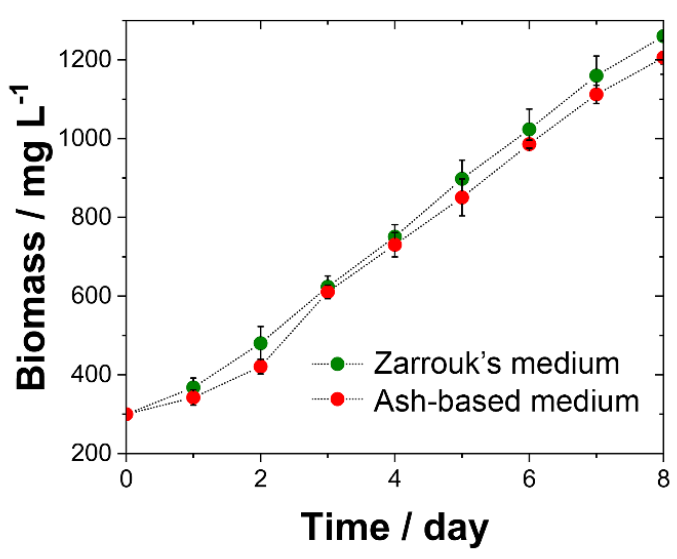

C

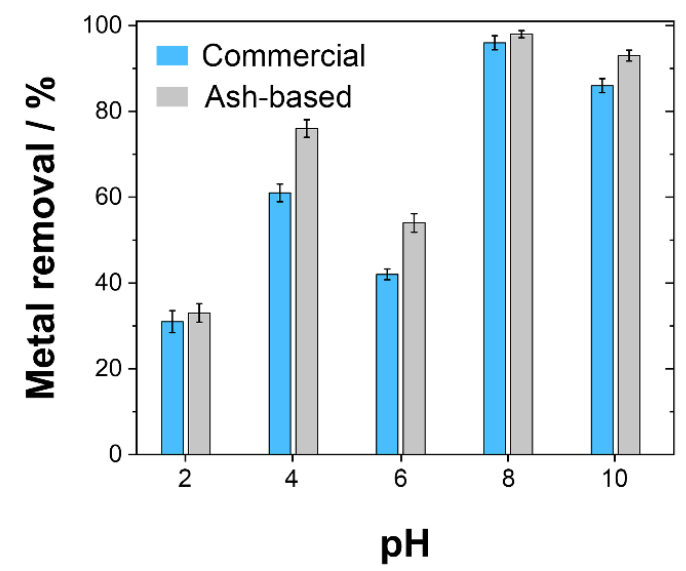

b

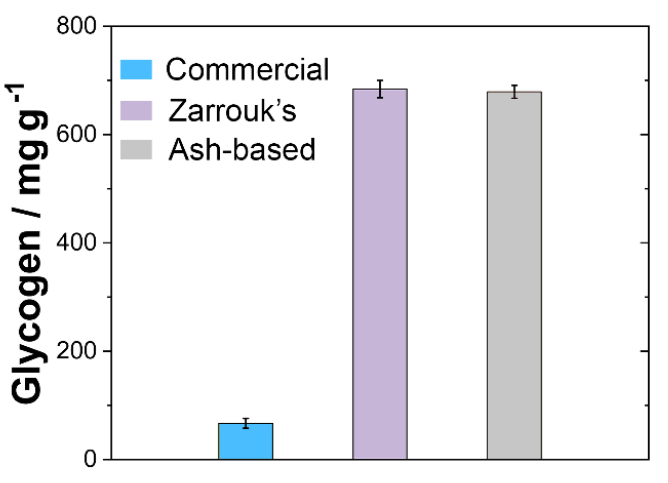

d

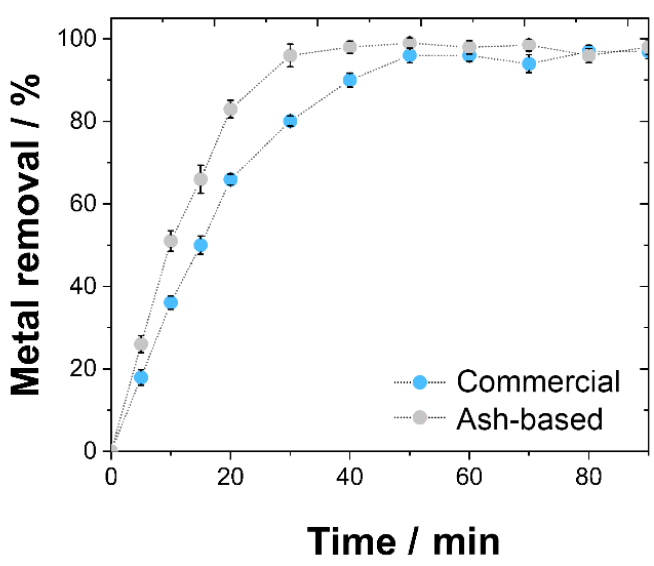

Figure 2: (a) Microalgal biomass production in nitrate-deficient Zarrouk's medium (4 $\left.\mathrm{mM} \mathrm{NaNO}_{3}\right)$ and an ash-based medium. (b) Glycogen content of commercial Spirulina powder (A. platensis), A. platensis cultivated in nitrate-deficient Zarrouk's medium, and Spirulina grown in the ash-based medium. (c) pHdependent removal of iron ions (40 ppm) observed for $0.8 \mathrm{~g} \mathrm{~L}^{-1}$ of commercial Spirulina powder and A. platensis grown in the ash-based medium after 90 min at $25.1 \pm 0.1{ }^{\circ} \mathrm{C}$. (d) Time-dependent removal of iron ions (40 ppm) by $0.8 \mathrm{~g} \mathrm{~L}^{-1}$ commercial Spirulina powder and A. platensis grown in the ash-based medium at $\mathrm{pH} 8$ and $25.1 \pm 0.1{ }^{\circ} \mathrm{C}$. Data points and error bars are the mean values of the three cultures and corresponding standard deviations, respectively.

\subsection{Heavy metal bioremediation}

A. platensis biomass has been proposed as an efficient biosorbent for heavy metal bioremediation [3335]. For this purpose, commercial Spirulina powder (A. platensis) and A. platensis var lonar cultivated 
in an ash-based medium (Figure S1) were tested for heavy metal bioremediation in a single-polluted aqueous solution of $\mathrm{FeCl}_{2}\left(40 \mathrm{mg} \mathrm{L}^{-1} ; 98 \%\right.$, Sigma-Aldrich) and multi-polluted real wastewater from the main drain of a local electroplating industry. In the case of the real effluent, reduction of the concentrations of $\mathrm{Cu}(\mathrm{II}), \mathrm{Ni}(\mathrm{II}), \mathrm{Zn}(\mathrm{II})$, and $\mathrm{Cr}(\mathrm{VI})$ after the bioremediation process was analyzed.

For the single pollutant solution, the bioaccumulation was evaluated as a function of $\mathrm{pH}$ and contact time. Several mechanisms of heavy metal bioaccumulation have been proposed, based on the activity (active or passive) of surface adsorption and intracellular bioaccumulation; normally the two processes coexist [36-38]. The $\mathrm{pH}$ of the medium plays a key role in bioaccumulation, as it determines the activity of functional groups on the surface of the microalgal biomass as well as the degree of ionization and speciation of heavy metals. In this study, functional groups were analyzed by Fourier-transform infrared spectroscopy (Figure S2), which revealed the presence of amino, carboxyl, hydroxyl, phosphate, and sulfate moieties as the main functional groups in both types of Spirulina. As seen in Figure 2c, the total iron removal primarily depended on $\mathrm{pH}$, being highest at $\mathrm{pH} 8-10$. At lower $\mathrm{pH}$ values, various negatively charged functional groups (mainly carboxyl) were protonated, which decreased the binding site availability and prevented iron ions from effectively competing with protons.

The above results highlight the importance of biosorption, which is seemingly governed by the exchange between protons and iron ions, in the uptake mechanism [39, 40]. The importance of biosorption in this bioaccumulation process is strengthened by the short contact time required for iron removal (Figure 2d). However, the non-depreciable removal activity under strongly acidic conditions, under which little or no uptake is expected, also adds to the low desorption of iron $(<40 \%)$ under these conditions, which indicates that intracellular accumulation also plays an important role in the employed bioremediation process. Both types of Spirulina presented excellent biosorption capabilities, achieving removal efficiencies of $>97 \%$ after 90 min of microalgae contact with the metal ion solution (Figure 2d).

Additionally, to prove the heavy metal bioremediation capability of Spirulina a real electroplating wastewater was used as a test solution. The wastewater was filtered, diluted to a final $\mathrm{Cu}$ (II) concentration of $80 \mathrm{mg} \mathrm{L}^{-1}(\mathrm{Cu}$ (II) was the main pollutant of our samples), and adjusted to a $\mathrm{pH}$ of 4 before 
bioremediation. After $90 \mathrm{~min}$ at $25.1 \pm 0.1{ }^{\circ} \mathrm{C}$ in contact with Spirulina, the metal removal values for $\mathrm{Cu}(\mathrm{II}), \mathrm{Ni}(\mathrm{II}), \mathrm{Zn}(\mathrm{II})$ and $\mathrm{Cr}(\mathrm{VI})$ were $68,75,42$, and $24 \%$, respectively, for ash-based Spirulina and 57, 70, 36, and $16 \%$, respectively, for commercial Spirulina.

Therefore, Spirulina is an effective, low-cost, and sustainable biosorbent for heavy metal removal from wastewater. In this circular process, the microalgal biomass used for heavy metal bioremediation is then recycled to produce bioethanol.

\subsection{Bioethanol production}

Over the last two decades, microalgae have attracted much attention as a source of bioethanol. However, for industrial applications, ethanol production processes require improvement, especially for pretreatment (e.g., chemical, thermal, mechanical, or biological processes, and their combination) [5, 17-19]. Pretreatment promotes cell disruption and thus facilitates the extraction of intracellular carbohydrates which determine the bioethanol production. Mechanical pretreatment methods (e.g. high-pressure homogenization, hydrodynamic cavitation, and bead milling) are the most common used in industry, as they are usually the most attractive in economic and environmental terms. However, mechanical pretreatment is both expensive and complex $[41,42]$. Bioethanol production from microalgae can be made more viable on an industrial scale (parallel to its optimization) by reducing raw material costs, recycling waste generated by other processes, and reusing the generated residues for other applications. Therefore, the integration of bioethanol production is expected to afford an efficient and economical circular process.

This work aimed to study the potential use of the iron- and glycogen-rich residual microalgal biomass obtained after heavy metal bioremediation for effective bioethanol production. The recycled microalgal biomass was dispersed in yeast extract peptone medium (Formedium, Hunstanton, UK) and subjected to physical lysing using a simple homogenizer to extract glycogen and glucose. The ease of Spirulina fragmentation showed that the mechanical process selected to extract carbohydrates was simple, economical, and industrially scalable. Next, to simplify the process, bioethanol production was carried out through simultaneous saccharification and fermentation (SSF) under two different conditions, namely 
(i) the direct use of a liquid-triturated biomass mixture (i.e., without filtering) and (ii) after biomass filtering and separation of the glycogen- and glucose-containing supernatants.

a

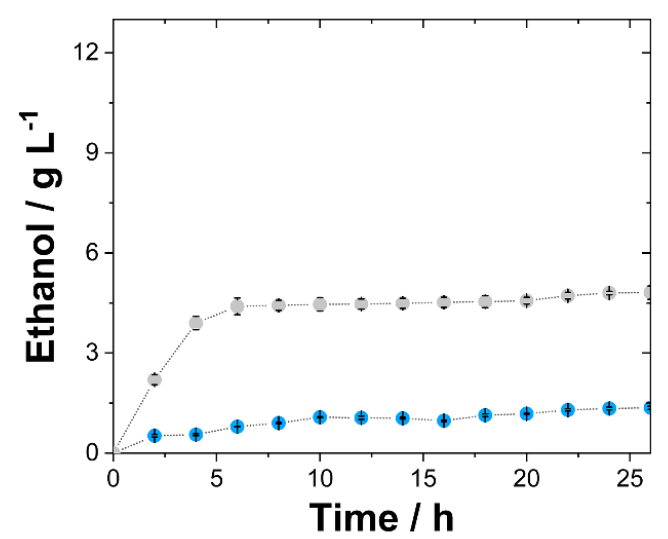

-. Commercial Spirulina b

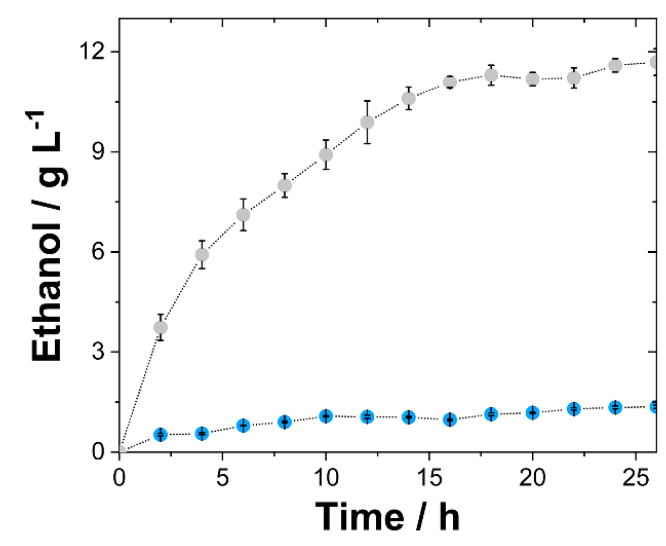

Ash-based Spirulina

Figure 3: Ethanol production from glycogen and glucose contained in recycled commercial Spirulina powder and recycled Spirulina grown in an ash-based medium. Results were obtained in the (a) presence and (b) absence of microalgal biomass at $1.5 \mathrm{U} \mathrm{L}^{-1}$ of $\alpha$-glucosidase, $3.5 \mathrm{U} \mathrm{L}^{-1}$ of $\alpha$-amylase, and $\sim 1.55 \times 10^{7}$ yeast $\mathrm{mL}^{-1}$ of Ethanol Red. Data points and error bars are the mean values of the three separate cultures and corresponding standard deviations, respectively.

The SSF step was carried out using $\alpha$-glucosidase and $\alpha$-amylase for saccharification (i.e., the conversion of glycogen to glucose) and a commercial industrial yeast (strains of Saccharomyces cerevisiae, Ethanol Red) for microbial fermentation (i.e., the conversion of glucose to ethanol), and the results are shown in Figure 3. In both cases, the initial glucose and glycogen concentrations were virtually identical ( $\sim 1.4 \mathrm{~g} \mathrm{~L}^{-1}$ of glucose and $\sim 2.5 \mathrm{~g} \mathrm{~L}^{-1}$ of glycogen for commercial Spirulina powder and $\sim 0.8 \mathrm{~g} \mathrm{~L}^{-1}$ of glucose and $\sim 26.7 \mathrm{~g} \mathrm{~L}^{-1}$ of glycogen for Spirulina grown in the ash-based medium). Without biomass filtration, bioethanol production of $1.21 \pm 0.09$ and $4.8 \pm 0.2 \mathrm{~g} \mathrm{~L}^{-1}$ were observed for commercial and cultivated microalgae, respectively. However, when the biomass was separated, the respective values increased to $1.36 \pm 0.05$ and $11.7 \pm 0.4 \mathrm{~g} \mathrm{~L}^{-1}$. These differences were attributed to the reabsorption of glycogen and glucose molecules, the absorption of produced ethanol, and/or the inhibition of the SSF 
process by biomass. Consequently, the biomass should be separated from supernatants before the SSF process onset.

The excellent ethanol production ( $\sim 90 \%$ of the theoretical value) observed for Spirulina grown in the ash-based medium ( $\sim .4 \mathrm{~L}$ per $\mathrm{kg}$ of dried microalgal biomass) was comparable to or even higher than those obtained for other carbon feedstocks (Table S3) [18, 42-48]. Consequently, these results reinforce the potential of the proposed circular process. The generated residual biomass was subsequently used to fabricate biomass pellets, and the concomitantly produced carbon dioxide was used to cultivate more Spirulina, making the ethanol production a zero-residue process.

\subsection{Pelletization and pyrolysis of residual microalgal biomass}

The residual microalgal biomass from bioethanol production was used to fabricate solid biofuel (nonwoody) pellets. Before producing pellets, although not explored here, high value chemicals such as lipids, pigments, antioxidants, vitamins, or proteins, can be extracted. Pellet production is typically performed in multiple steps including harvesting, pretreatment, pelletization, and post-treatment, with the most expensive step being pretreatment, especially biomass drying. Herein, microalgal pellets were produced by a simple pelletizing process based on (1) the collection of fragmented residual biomass from bioethanol production, (2) sunlight irradiation to dry the biomass and reduce its moisture content to 1015 wt. \%, and (3) pellet manufacturing by biomass compression using a single pelletizer. During the last step, the temperature considerably increased because of the high pressure, and several microalgal components (such as lignin) acted as binding agents for biomass fibers to enhance the pellet quality and pelletization without the use of artificial binders. Figure 3a shows that well-defined microalgal pellets were easily obtained from the residues of commercial or ash-based Spirulina. 
a
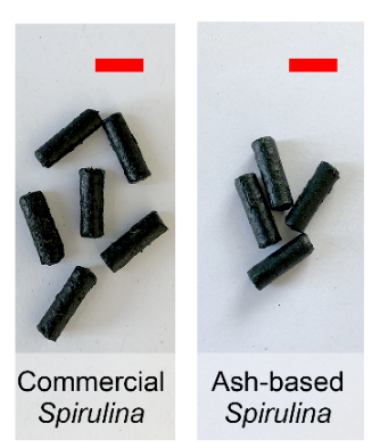

b

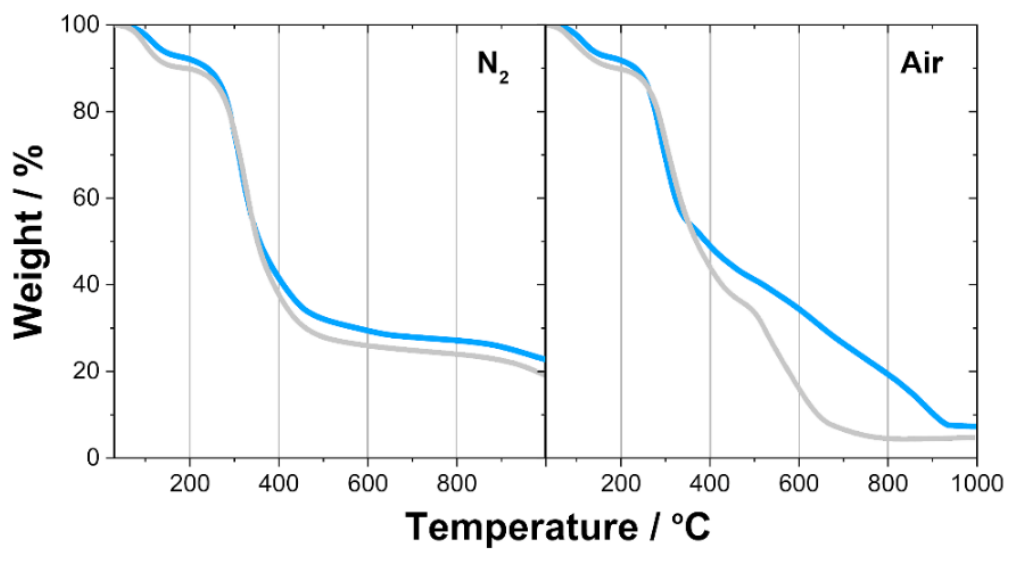

- Commercial Spirulina Ash-based Spirulina

Figure 4: (a) Photographs of commercial Spirulina (left) and ash-based Spirulina (right) pellets. Scale bar: $1 \mathrm{~cm}$. (b) Thermogravimetric analysis (TGA) profiles of commercial Spirulina and ash-based Spirulina pellets recorded in nitrogen and air environments

Table 1: Physicochemical properties of the manufactured Spirulina pellets.

\begin{tabular}{|c|c|c|c|c|}
\hline $\begin{array}{c}\text { Microalgal bio- } \\
\text { mass }\end{array}$ & Spirulina species & Ash / wt. \% & Humidity / & Calorific power / \\
wt. \% & MJ kg $^{-\mathbf{1}}$ \\
\hline $\begin{array}{c}\text { Commercial Spir- } \\
\text { ulina powder }\end{array}$ & A. platensis & $5.9 \pm 0.1$ & $6.5 \pm 0.3$ & $19.9 \pm 0.2$ \\
\hline $\begin{array}{c}\text { Cultivated Spir- } \\
\text { ulina }\end{array}$ & A. platensis var lonar & $5.5 \pm 0.1$ & $5.1 \pm 0.2$ & $20.6 \pm 0.2$ \\
\hline
\end{tabular}

The physicochemical properties of the manufactured pellets such as ash content, moisture content, and calorific power, were analyzed (Table 1) and compared with those stipulated by ISO 17225-6:2014 for non-woody pellets (ash content $<10$ wt. \%, moisture content $<15$ wt. \%, calorific power $>14.5 \mathrm{MJ}$ $\left.\mathrm{kg}^{-1}\right)$. These requirements must be fulfilled for the cultivated microalgae to be considered as a commercial biofuel and be used as a fuel in biomass boilers [49]. Our microalgal pellets complied with the 
abovementioned requirements and are therefore proposed as an effective solid biofuel. The calorific power of the microalgal pellets was comparable to or even higher than that of other solid biomass fuels such as those obtained from agricultural or forestry crops [50-53].

In addition, the thermal degradation of both commercial and ash-based Spirulina pellets in nitrogen and air was investigated by thermogravimetric analysis (TGA) (Figure 3b) to confirm their viability as a solid biofuel. Three weight loss steps were observed, which were more evident in the nitrogen environment. The first step (room temperature to $175{ }^{\circ} \mathrm{C}$ ) corresponding to a weight loss of $\sim 7.5 \%$ and was attributed to the vaporization of water and volatiles. The second step $\left(175-725^{\circ} \mathrm{C}\right)$ corresponded to a weight loss of $\sim 65 \%$ and $75 \%$ in nitrogen and air atmospheres, respectively, was attributed to the carbonization of carbohydrates and proteins. The biomass weight rapidly decreased for temperatures above $300{ }^{\circ} \mathrm{C}$ until it began to slow at $450{ }^{\circ} \mathrm{C}$. Consequently, two stages attributable to the thermal decomposition of carbohydrates and sulfur/nitrogen release upon protein degradation were observed. Note that thermal degradation was higher in air (i.e., in a more oxidizing environment). The continuous weight loss (especially in air) observed above $725^{\circ} \mathrm{C}$ was attributed to the slow combustion of partly carbonized residue or metal reduction, with 5.9 and 5.5 wt. \% of ash (Figure S3) obtained for commercial and cultivated microalgae, respectively. The chemical composition of microalgal ash is summarized in Table S1. Thus, microalgal biomass pellets are easily fabricated and combusted as solid biofuel for energy applications to produce a small amount of residue suitable for water decontamination and microalgal cultivation. The carbon dioxide produced during combustion can also be fixated during microalgal cultivation.

\subsection{Solar photo-Fenton remediation of persistent organic pollutants}

The aim of the next stage of the circular process is the total mineralization of persistent organic pollutants into carbon dioxide, water, and inorganic ions to decontaminate wastewater using the Fenton process catalyzed by the recycled iron-rich ash from microalgal pellet combustion. The mineralization process was based on the classical Fenton reaction (Eq. 1) [54-57]:

$$
\mathrm{Fe}^{2+}+\mathrm{H}_{2} \mathrm{O}_{2}+\mathrm{H}^{+} \rightarrow \mathrm{Fe}^{3+}+\cdot \mathrm{OH}+\mathrm{H}_{2} \mathrm{O}
$$


The hydroxyl radicals $\left({ }^{\bullet} \mathrm{OH}\right)$ formed during this process are powerful non-selective oxidants that can completely mineralize most organic pollutants to carbon dioxide, inorganic ions, and water. In addition, irradiation, especially with ultraviolet A light, is known to accelerate mineralization, mainly by promoting the direct photoreduction of iron (III)-hydroxo complexes (known as the photo-Fenton reaction) and consequently regenerating the $\mathrm{Fe}(\mathrm{II})$ catalyst and producing more hydroxyl radicals [54-59]. Microalgal ashes rich in iron (see Table S1) could thus be used to remediate persistent organic pollutants. Methylene blue (MB) was selected as a probe and iron(II) chloride was used as a reference to examine the effectiveness of microalgal ashes in organic pollutant remediation.

As shown in Figure 5a, the microalgal ashes comprised porous non-spherical microparticles and exhibited BET (Brunauer-Emmett-Teller) surface areas of $6.8 \mathrm{~m}^{2} \mathrm{~g}^{-1}$ (commercial Spirulina) and $16.7 \mathrm{~m}^{2} \mathrm{~g}^{-1}$ (ash-based Spirulina) (Figure S4).

MB degradation was analyzed in the dark and under irradiation with UV or sunlight, as shown in Figure 5b and $\mathbf{c}$ and Table 2. In the absence of light, the degradation efficiencies reached 11.2, 2.8, and 25.2\% after 100 min of reaction time for iron (II) chloride, commercial and ash-based Spirulina ashes, respectively. In contrast, degradation efficiencies of 5.6 and $30.4 \%$ were obtained for commercial and ashbased Spirulina ashes, respectively, under the same conditions but with introduction of heterogeneous catalyst in the pollutant solution for $30 \mathrm{~min}$ before $\mathrm{H}_{2} \mathrm{O}_{2}$ addition. In the dark, the removal after $100 \mathrm{~min}$ (Figure S5) was negligible in the absence of catalysts (i.e., in the presence of only $\mathrm{H}_{2} \mathrm{O}_{2}$ ) but reached 1.8 and 5.3\% for commercial and ash-based Spirulina ashes, respectively, possibly as a consequence of pollutant adsorption. Moreover, the catalytic performance improved when the process was conducted under UV or solar irradiation, and the degradation exceeded $98 \%$ after 100 min of reaction time. The slower removal in the dark for the regeneration of iron(II) is ascribed to the significantly slower kinetics of the Fenton-like reaction (the reaction of hydrogen peroxide with ferric ions) compared to the photoreduction of iron(III)-hydroxo complexes and photodecarboxylation of iron(III)-carboxylate complexes. This Fenton-like reaction leads to the formation of hydroperoxyl radicals, a weak oxidant that cannot oxidize organic matter [54-59]. 
Mineralization was determined from the total organic content (TOC) reduction after 100 min of reaction time. The maximum mineralization was slightly lower than the MB degradation (Table 2), especially when the homogeneous catalyst was used.

Table 2: BET surface areas, iron contents, and photocatalytic MB (10 ppm) degradation of $0.1 \mathrm{~g} \mathrm{~L}^{-1}$ $\mathrm{FeCl}_{2}$ and commercial and ash-based Spirulina ashes at $20.1 \pm 0.2{ }^{\circ} \mathrm{C}$ in the dark and under UV light $(365 \mathrm{~nm})$ or solar light irradiation. Values in parentheses were obtained under the same conditions when the heterogeneous catalyst was incubated in the $\mathrm{MB}$ solution for 30 min before $\mathrm{H}_{2} \mathrm{O}_{2}$ addition.

\begin{tabular}{|c|c|c|c|c|c|c|c|c|}
\hline & \multirow{2}{*}{$\begin{array}{l}\text { BET } \\
\text { surface } \\
\text { area / } \\
\mathbf{m}^{2} \mathbf{g}^{-1}\end{array}$} & \multirow{2}{*}{$\begin{array}{c}\text { Iron con- } \\
\text { tent / } \\
\text { ppm }\end{array}$} & \multicolumn{2}{|c|}{ Fenton } & \multicolumn{2}{|c|}{$\begin{array}{l}\text { Photo-Fenton (UV irradia- } \\
\text { tion) }\end{array}$} & \multicolumn{2}{|c|}{$\begin{array}{c}\text { Photo-Fenton (solar irradia- } \\
\text { tion) }\end{array}$} \\
\hline & & & $\begin{array}{c}\text { MB deg- } \\
\text { radation } \\
/ \%\end{array}$ & $\begin{array}{c}\text { Mineraliza- } \\
\text { tion / \% }\end{array}$ & $\begin{array}{l}\text { MB degrada- } \\
\text { tion / \% }\end{array}$ & $\begin{array}{c}\text { Mineraliza- } \\
\text { tion / \% }\end{array}$ & $\begin{array}{c}\text { MB degrada- } \\
\text { tion / \% }\end{array}$ & $\begin{array}{c}\text { Mineraliza- } \\
\text { tion / \% }\end{array}$ \\
\hline $\begin{array}{l}\text { Iron (II) } \\
\text { chloride }\end{array}$ & - & 100 & $11.2 \pm 0.6$ & $6.2 \pm 0.3$ & $99.9 \pm 0.2$ & $81.4 \pm 0.2$ & $99.7 \pm 0.1$ & $77.2 \pm 0.2$ \\
\hline $\begin{array}{l}\text { Commer- } \\
\text { cial Spir- } \\
\text { ulina } \\
\text { ashes }\end{array}$ & 3.8 & $\sim 20$ & $\begin{array}{c}2.8 \pm 0.5 \\
(5.6 \pm 0.6)\end{array}$ & $1.1 \pm 0.4$ & $\begin{array}{c}99.6 \pm 0.1 \\
(99.8 \pm 0.1)\end{array}$ & $86.2 \pm 0.4$ & $\begin{array}{c}98.9 \pm 0.2 \\
(98.9 \pm 0.2)\end{array}$ & $79.4 \pm 0.3$ \\
\hline $\begin{array}{l}\text { Ash-based } \\
\text { Spirulina } \\
\text { ashes }\end{array}$ & 23.7 & $\sim 25$ & $\begin{array}{c}25.2 \pm 0.5 \\
(30.4 \pm \\
0.4)\end{array}$ & $14.3 \pm 0.3$ & $\begin{array}{c}99.9 \pm 0.1 \\
(99.9 \pm 0.2)\end{array}$ & $88.2 \pm 0.3$ & $\begin{array}{c}99.9 \pm 0.1 \\
(99.9 \pm 0.1)\end{array}$ & $82.1 \pm 0.2$ \\
\hline
\end{tabular}

The degradation and mineralization of heterogeneous catalysts, especially for ash-based Spirulina ashes (high surface area), were close to or greater than those of the homogeneous catalyst (100 ppm $\mathrm{FeCl}_{2}$ ), while the iron content of the heterogeneous systems was approximately five times lower. Depending on the heavy metal bioremediation process, microalgal ashes may contain other heavy metals. The Fenton process can be affected by other metals, for example, limited in the presence of $\mathrm{Ni}$ (II) ions or synergistically promoted in the presence of $\mathrm{Co}(\mathrm{II}), \mathrm{Cu}(\mathrm{II})$ or $\mathrm{Mn}(\mathrm{II})$ ions $[60,61]$.

Finally, the stability and reusability of the microalgal ashes were evaluated by reusing the catalyst in five consecutive MB degradation cycles (Figure 5d) under UV irradiation. No significant changes in MB degradation were observed during all successive runs, and an approximately $99 \%$ degradation was 
attained after five runs. The maximum mineralization was slightly reduced after cycling (from 86.2 to $77.4 \%$ for commercial Spirulina ashes and from 88.2 to $79.9 \%$ for ash-based Spirulina ashes), possibly because of the leaching of small amounts of metal ions during consecutive irradiation. Thus, we concluded that the recycled ashes produced by microalgal pellet combustion can be effectively (re)used as efficient catalysts to mineralize persistent organic pollutants.

a

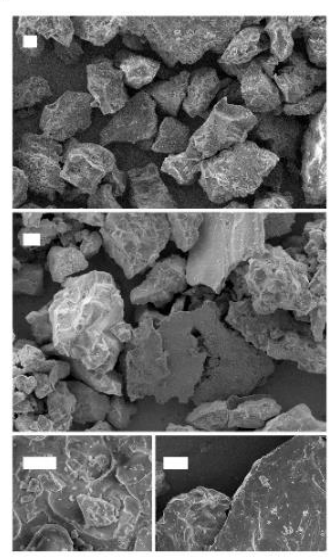

C

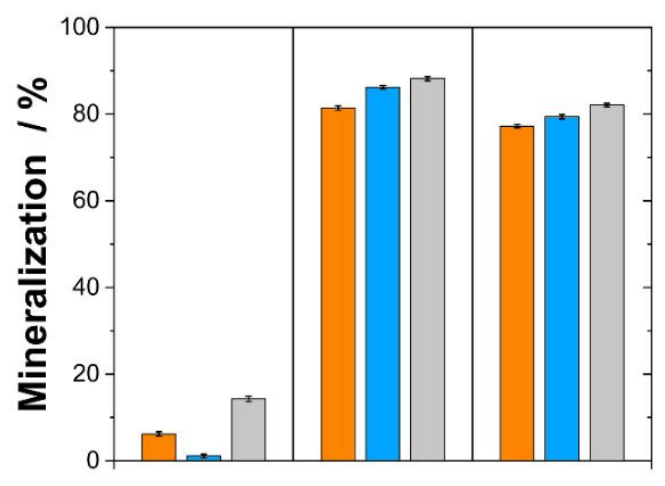

- $\mathrm{FeCl}_{2}$ b
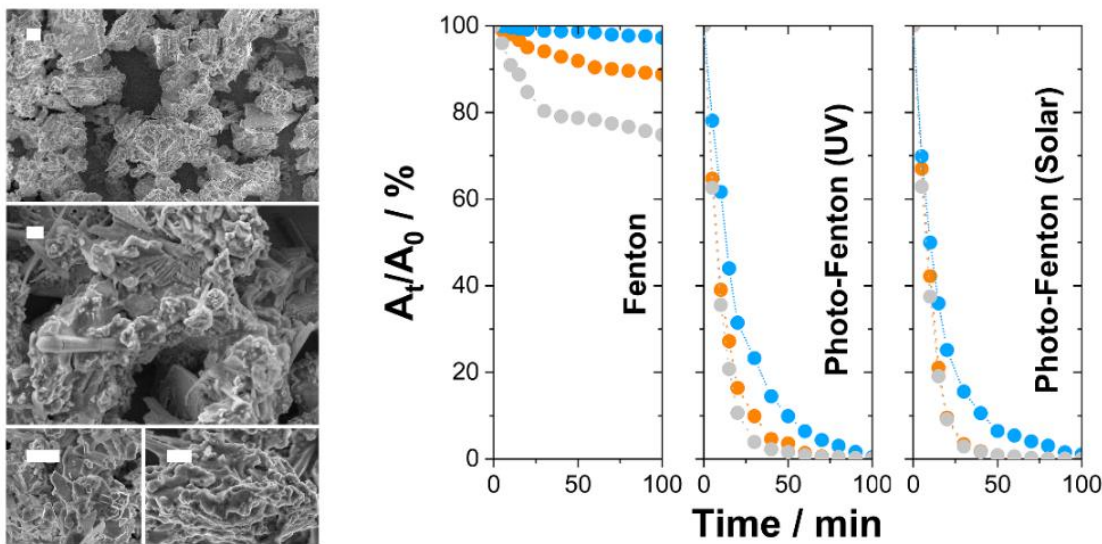

Time / min

d
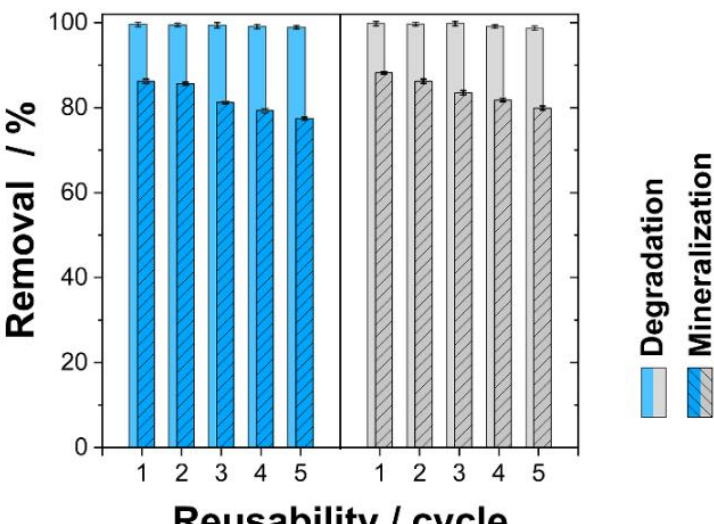

Reusability / cycle 
and commercial/ash-based Spirulina ashes. (d) Reusability (degradation and mineralization efficiencies after 100 min of reaction time) of commercial and ash-based Spirulina ashes for the UV photo-Fenton mineralization of MB.

\subsection{Closing the cycle - Microalgal cultivation}

To close the cycle, the carbon dioxide produced during bioethanol production, combustion, and mineralization of organic pollutants must be effectively used, fixed, and converted to value-added products during Spirulina cultivation. It is well known that carbon dioxide bubbling in microalgal cultivation tanks stimulates biomass production. The microalgal ashes used to mineralize persistent organic pollutants or decontaminate water were effectively used to prepare an ash-based medium to cultivate more Spirulina microalgae (Figure 1a). During this circular process, oxygen was consumed, and carbon dioxide was generated, but the entire circular process offered a positive balance in terms of carbon dioxide fixation and oxygen production. Therefore, clean water, oxygen, bioethanol, and energy were obtained, and no residues were produced.

\section{Conclusions}

A holistic circular process based on the principles of green and circular chemistry was developed by integrating atmospheric oxygen production, water decontamination, carbon dioxide fixation, and bioethanol/microalgal pellet production. This process mimics the algal life cycle and does not generate any waste, as the residues obtained in each phase are the starting material of the next phase. The circular process is based on the use of Spirulina microalgae and sunlight, which are extremely low-cost and sustainable, demonstrating the ease of implementation even in developing countries. The cultivated microalgae and decontaminated water can be used for other applications such as cosmetics or nutraceuticals, allowing for the integration of new phases to maximize economic viability. Furthermore, the extraction of valuable chemicals before pelletization is a potential avenue for improving the profitability. 
This circular process can easily be scaled up for industrial applications with minimal infrastructure investment and limited resources. Importantly, this circular process is not limited to Spirulina as other microalgae (or mixtures of various microalgae) can also be used.

\section{Acknowledgements}

This work was partially supported by the Metrohm foundation. Partial funding from the TEC201785059-C3-2-R project (co-financed by the Fondo Europeo de Desarrollo Regional, FEDER) from the Spanish Ministerio de Economía y Competitividad (MINECO) is also acknowledged. Albert Serrà would like to acknowledge funding from the EMPAPOSTDOCS-II program. The EMPAPOSTDOCSII programme has received funding from the European Union's Horizon 2020 research and innovation programme under the Marie Skłodowska-Curie grant agreement number 754364.

\section{Appendix A. Supplementary data}

Supplementary data related to this article can be found, in the online version, at doi:

\section{References}

[1] M.I. Khan, J.H. Shin, J.D. Kim, The promising future of microalgae: Current status, challenges, and optimization of a sustainable and renewable industry for biofuels, feed, and other products, Microb. Cell Fact. 17 (2018) 1-21. doi:10.1186/s12934-018-0879-x.

[2] T. Keijer, V. Bakker, J.C. Slootweg, Circular chemistry to enable a circular economy, Nat. Chem. 11 (2019) 190-195. doi:10.1038/s41557-019-0226-9.

[3] K.W. Chew, J.Y. Yap, P.L. Show, N.H. Suan, J.C. Juan, T.C. Ling, D.J. Lee, J.S. Chang, Microalgae biorefinery: High value products perspectives, Bioresour. Technol. 229 (2017) 5362. doi:10.1016/j.biortech.2017.01.006.

[4] A.K. Zeraatkar, H. Ahmadzadeh, A.F. Talebi, N.R. Moheimani, M.P. McHenry, Potential use of algae for heavy metal bioremediation, a critical review, J. Environ. Manage. 181 (2016) 817-831. doi:10.1016/j.jenvman.2016.06.059.

[5] T. Suganya, M. Varman, H.H. Masjuki, S. Renganathan, Macroalgae and microalgae as a potential source for commercial applications along with biofuels production: A biorefinery approach, Renew. Sustain. Energy Rev. 55 (2016) 909-941. doi:10.1016/j.rser.2015.11.026.

[6] S. Chinnasamy, A. Bhatnagar, R.W. Hunt, K.C. Das, Microalgae cultivation in a wastewater dominated by carpet mill effluents for biofuel applications, Bioresour. Technol. 101 (2010) 3097-3105. doi:10.1016/j.biortech.2009.12.026. 
[7] M.G. de Morais, J.A.V. Costa, Biofixation of carbon dioxide by Spirulina sp. and Scenedesmus obliquus cultivated in a three-stage serial tubular photobioreactor, J. Biotechnol. 129 (2007) 439-445. doi:10.1016/j.jbiotec.2007.01.009.

[8] D.F. Lozano-Garcia, S.P. Cuellar-Bermudez, E. del Rio-Hinojosa, F. Betancourt, G.S. Aleman-Nava, R. Parra-Saldivar, Potential land microalgae cultivation in Mexico: From food production to biofuels, Algal Res. 39 (2019). doi:10.1016/j.algal.2019.101459.

[9] R. García-Cubero, J. Moreno-Fernández, M. García-González, Modelling growth and $\mathrm{CO}_{2}$ fixation by Scenedesmus vacuolatus in continuous culture, Algal Res. 24 (2017) 333-339. doi:10.1016/j.algal.2017.04.018.

[10] R.L. Chapman, Algae: The world's most important "plants"-an introduction, Mitig. Adapt. Strateg. Glob. Chang. 18 (2013) 5-12. doi:10.1007/s11027-010-9255-9.

[11] U.B. Singh, A.S. Ahluwalia, Microalgae: A promising tool for carbon sequestration, Mitig. Adapt. Strateg. Glob. Chang. 18 (2013) 73-95. doi:10.1007/s11027-012-9393-3.

[12] D. Sadovsky, A. Brenner, B. Astrachan, B. Asaf, R. Gonen, Biosorption potential of cerium ions using Spirulina biomass, J. Rare Earths. 34 (2016) 644-652. doi:10.1016/S10020721(16)60074-1.

[13] E. Gunasundari, S.K. P., Adsorption isotherm, kinetics and thermodynamic analysis of $\mathrm{Cu}(\mathrm{II})$ ions onto the dried algal biomass (Spirulina platensis), J. Ind. Eng. Chem. 56 (2017) 129-144. doi:10.1016/j.jiec.2017.07.005.

[14] R. Razmovski, M. Šćiban, Iron(III) biosorption by Polyporus squamosus, African J. Biotechnol. 7 (2008) 1693-1699. doi:10.5897/AJB2008.000-5026.

[15] Z. Aksu, Ü. Açikel, Modelling of a single-staged bioseparation process for simultaneous removal of iron(III) and chromium(VI) by using Chlorella vulgaris, Biochem. Eng. J. 4 (2000) 229-238. doi:10.1016/S1369-703X(99)00053-4.

[16] M. Koller, A. Muhr, G. Braunegg, Microalgae as versatile cellular factories for valued products, Algal Res. 6 (2014) 52-63. doi:10.1016/j.algal.2014.09.002.

[17] F. Martínez-Jerónimo, D.I. Flores-Hernández, J. Galindez-Mayer, Formulation of an Alternative Culture Medium for Arthrospira maxima (Spirulina) Based on "Tequesquite," a Traditional Mineral Resource, J. World Aquac. Soc. 48 (2017) 887-897. doi:10.1111/jwas.12362.

[18] S. Aikawa, A. Joseph, R. Yamada, Y. Izumi, T. Yamagishi, F. Matsuda, H. Kawai, J.S. Chang, T. Hasunuma, A. Kondo, Direct conversion of Spirulina to ethanol without pretreatment or enzymatic hydrolysis processes, Energy Environ. Sci. 6 (2013) 1844-1849. doi:10.1039/c3ee40305j.

[19] E.S. Salama, M.B. Kurade, R.A.I. Abou-Shanab, M.M. El-Dalatony, I.S. Yang, B. Min, B.H. Jeon, Recent progress in microalgal biomass production coupled with wastewater treatment for biofuel generation, Renew. Sustain. Energy Rev. 79 (2017) 1189-1211. doi:10.1016/j.rser.2017.05.091.

[20] J.Y. Lee, C. Yoo, S.Y. Jun, C.Y. Ahn, H.M. Oh, Comparison of several methods for effective lipid extraction from microalgae, Bioresour. Technol. 101 (2010) S75-S77. doi:10.1016/j.biortech.2009.03.058.

[21] N. Pragya, K.K. Pandey, P.K. Sahoo, A review on harvesting, oil extraction and biofuels production technologies from microalgae, Renew. Sustain. Energy Rev. 24 (2013) 159-171. doi:10.1016/j.rser.2013.03.034.

[22] A. Serrà, Y. Zhang, B. Sepúlveda, E. Gómez, J. Nogués, J. Michler, L. Philippe, Highly reduced ecotoxicity of $\mathrm{ZnO}$-based micro/nanostructures on aquatic biota: Influence of architecture, chemical composition, fixation, and photocatalytic efficiency, Water Res. 169 (2020). doi:10.1016/j.watres.2019.115210. 
[23] H.K. Lichtenthaler, Chlorophylls Carotenoids, Chlorophylls Carotenoids Pigment. Photosynth. Biomembr. 148 (1987) 350-382. doi: 10.1016/0076-6879(87)48036-1

[24] S. Dere, T. Gunes, R. Sivaci, Spectrophotometric determination of chlorophyll - A, B and total carotenoid contents of some algae species using different solvents. Turk. J. Bot., 22 (1998) 1317. doi:10.1080/19393550802541200

[25] A. Serrà, R. Artal, J. Garcia-Amoros, B. Sepulveda, E. Gomez, J. Nogues, L. Philippe. Hybrid Ni@ZnO@ZnS-Microalgae for circular economy: A smart route to the efficient integration of solar photocatalytic water decontamination and bioethanol production, Adv. Sci. 1902447 (2019). doi:10.1002/advs.201902447.

[26] X.Q. Zhao, R.C. Wang, X.C. Lu, J.J. Lu, J. Li, H. Hu, Tolerance and biosorption of heavy metals by cupriavidus metallidurans strain XXKD-1 isolated from a subsurface laneway in the qixiashan Pb-Zn sulfide minery in eastern china, Geomicrobiol. J. 29 (2012) 274-286. doi:10.1080/01490451.2011.619637.

[27] C.E. de Farias Silva, A. Bertucco, Bioethanol from microalgae and cyanobacteria: A review and technological outlook, Process Biochem. 51 (2016) 1833-1842. doi:10.1016/j.procbio.2016.02.016.

[28] J.R. Benavente-Valdés, C. Aguilar, J.C. Contreras-Esquivel, A. Méndez-Zavala, J. Montañez, Strategies to enhance the production of photosynthetic pigments and lipids in chlorophycae species, Biotechnol. Reports. 10 (2016) 117-125. doi:10.1016/j.btre.2016.04.001.

[29] G. Usharani, P. Saranraj, D. Kanchana, In vitro Cultivation of Spirulina platensis using Rice Mill Effluent, Int. J. Pharm. Biol. 3 (2012) 1518-1523.

[30] Y. Li, M. Horsman, B. Wang, N. Wu, C.Q. Lan, Effects of nitrogen sources on cell growth and lipid accumulation of green alga Neochloris oleoabundans, Appl. Microbiol. Biotechnol. 81 (2008) 629-636. doi:10.1007/s00253-008-1681-1.

[31] S. Jain, S.G. Singh, Low cost medium formulation using cow dung ash for the cultivation of cyanobacterium: Spirulina (Arthrospira) platensis, Emirates J. Food Agric. 25 (2013) 682691. doi:10.9755/ejfa.v25i9.16394.

[32] F. Martínez-Jerónimo, D.I. Flores-Hernández, J. Galindez-Mayer, Formulation of an Alternative Culture Medium for Arthrospira maxima (Spirulina) Based on "Tequesquite," a Traditional Mineral Resource, J. World Aquac. Soc. 48 (2017) 887-897. doi:10.1111/jwas.12362.

[33] H. Chen, S.S. Pan, Bioremediation potential of spirulina: Toxicity and biosorption studies of lead, J. Zhejiang Univ. Sci. 6 B (2005) 171-174. doi:10.1631/jzus.2005.B0171.

[34] H. Rezaei, Biosorption of chromium by using Spirulina sp., Arab. J. Chem. 9 (2016) 846-853. doi:10.1016/j.arabjc.2013.11.008.

[35] A. Çelekli, M. Yavuzatmaca, H. Bozkurt, An eco-friendly process: Predictive modelling of copper adsorption from aqueous solution on Spirulina platensis, J. Hazard. Mater. 173 (2010) 123-129. doi:10.1016/j.jhazmat.2009.08.057.

[36] B. Volesky, Biosorption and me, Water Res. 41 (2007) 4017-4029. doi:10.1016/j.watres.2007.05.062.

[37] V. Subramaniyam, S.R. Subashchandrabose, P. Thavamani, Z. Chen, G.S.R. Krishnamurti, R. Naidu, M. Megharaj, Toxicity and bioaccumulation of iron in soil microalgae, J. Appl. Phycol. 28 (2016) 2767-2776. doi:10.1007/s10811-016-0837-0.

[38] K. Chojnacka, Bioaccumulation of Cr ( III ) ions by Blue-Green alga Spirulina sp . Part I . A Comparison with Biosorption Institute of Inorganic Technology and Mineral Fertilizers, Wroclaw University of Technology, Technology. 2 (2007) 218-223.

[39] C. Dong, Y. Wang, H. Zhang, S.Y. Leu, Feasibility of high-concentration cellulosic bioethanol production from undetoxified whole Monterey pine slurry, Bioresour. Technol. 250 (2018) 102-109. doi:10.1016/j.biortech.2017.11.029. 
[40] A. Esposito, F. Pagnanelli, F. Vegliò, pH-related equilibria models for biosorption in single metal systems, Chem. Eng. Sci. 57 (2002) 307-313. doi:10.1016/S0009-2509(01)00399-2.

[41] M. Ebrahimi, A.R. Caparanga, O.B. Villaflores, Weak base pretreatment on coconut coir fibers for ethanol production using a simultaneous saccharification and fermentation process, Biofuels. 7269 (2018) 1-7. doi:10.1080/17597269.2018.1468979.

[42] M.A. Ahmed, M.S.U. Rehman, R. Terán-Hilares, S. Khalid, J.I. Han, Optimization of twin gear-based pretreatment of rice straw for bioethanol production, Energy Convers. Manag. 141 (2017) 120-125. doi:10.1016/j.enconman.2016.06.022.

[43] S. Talekar, A.F. Patti, R. Vijayraghavan, A. Arora, An integrated green biorefinery approach towards simultaneous recovery of pectin and polyphenols coupled with bioethanol production from waste pomegranate peels, Bioresour. Technol. 266 (2018) 322-334. doi:10.1016/j.biortech.2018.06.072.

[44] Y. Li, P. Liu, J. Huang, R. Zhang, Z. Hu, S. Feng, Y. Wang, L. Wang, T. Xia, L. Peng, Mild chemical pretreatments are sufficient for bioethanol production in transgenic rice straws overproducing glucosidase, Green Chem. 20 (2018) 2047-2056. doi:10.1039/c8gc00694f.

[45] E. Derman, R. Abdulla, H. Marbawi, M.K. Sabullah, Oil palm empty fruit bunches as a promising feedstock for bioethanol production in Malaysia, Renew. Energy. 129 (2018) 285-298. doi:10.1016/j.renene.2018.06.003.

[46] J.O. Virgínio-Silva, M.F. Almeida, M. da Conceição Alvim-Ferraz, J.M. Dias, Integrated production of biodiesel and bioethanol from sweet potato, Renew. Energy. 124 (2018) 114-120. doi:10.1016/j.renene.2017.07.052.

[47] Y.K. Oh, K.R. Hwang, C. Kim, J.R. Kim, J.S. Lee, Recent developments and key barriers to advanced biofuels: A short review, Bioresour. Technol. 257 (2018) 320-333. doi:10.1016/j.biortech.2018.02.089.

[48] P. Álvarez, J.L. Salgueiro, L. Pérez, A. Cancela, A. Sánchez, L. Ortiz, Total use of microalgae as feedstock for biodiesel and pellet production, Int. J. Environ. Res. 10 (2016) 637-644.

[49] Y. Tsuchiya, T. Yoshida, Pelletization of brown coal and rice bran in Indonesia: Characteristics of the mixture pellets including safety during transportation, Fuel Process. Technol. 156 (2017) 68-71. doi:10.1016/j.fuproc.2016.10.009.

[50] M. V. Gil, P. Oulego, M.D. Casal, C. Pevida, J.J. Pis, F. Rubiera, Mechanical durability and combustion characteristics of pellets from biomass blends, Bioresour. Technol. 101 (2010) 8859-8867. doi:10.1016/j.biortech.2010.06.062.

[51] C. Serrano, E. Monedero, M. Lapuerta, H. Portero, Effect of moisture content, particle size and pine addition on quality parameters of barley straw pellets, Fuel Process. Technol. 92 (2011) 699-706. doi:10.1016/j.fuproc.2010.11.031.

[52] L.J.R. Nunes, J.C.O. Matias, J.P.S. Catalão, A review on torrefied biomass pellets as a sustainable alternative to coal in power generation, Renew. Sustain. Energy Rev. 40 (2014) 153-160. doi:10.1016/j.rser.2014.07.181.

[53] E. Brillas, I. Sirés, M.A. Oturan, Electro-Fenton process and related electrochemical technologies based on fenton's reaction chemistry, Chem. Rev. 109 (2009) 6570-6631. doi:10.1021/cr900136g.

[54] Y. Wang, H. Zhao, G. Zhao, Iron-copper bimetallic nanoparticles embedded within ordered mesoporous carbon as effective and stable heterogeneous Fenton catalyst for the degradation of organic contaminants, Appl. Catal. B Environ. 164 (2015) 396-406. doi:10.1016/j.apcatb.2014.09.047.

[55] C. Amor, E. De Torres-Socías, J.A. Peres, M.I. Maldonado, I. Oller, S. Malato, M.S. Lucas, Mature landfill leachate treatment by coagulation/flocculation combined with Fenton and solar 
photo-Fenton processes, J. Hazard. Mater. 286 (2015) 261-268. doi:10.1016/j.jhazmat.2014.12.036.

[56] Y. Liu, W. Jin, Y. Zhao, G. Zhang, W. Zhang, Enhanced catalytic degradation of methylene blue by A-Fe 2 O 3 /graphene oxide via heterogeneous photo-Fenton reactions, Appl. Catal. B Environ. 206 (2017) 642-652. doi:10.1016/j.apcatb.2017.01.075.

[57] A. Zhang, N. Wang, J. Zhou, P. Jiang, G. Liu, Heterogeneous Fenton-like catalytic removal of p-nitrophenol in water using acid-activated fly ash, J. Hazard. Mater. 201-202 (2012) 68-73. doi:10.1016/j.jhazmat.2011.11.033.

[58] S. Garcia-Segura, L.M. Bellotindos, Y.H. Huang, E. Brillas, M.C. Lu, Fluidized-bed Fenton process as alternative wastewater treatment technology - A review, J. Taiwan Inst. Chem. Eng. 67 (2016) 211-225. doi:10.1016/j.jtice.2016.07.021.

[59] A.M.S. Solano, S. Garcia-Segura, C.A. Martínez-Huitle, E. Brillas, Degradation of acidic aqueous solutions of the diazo dye Congo Red by photo-assisted electrochemical processes based on Fenton's reaction chemistry, Appl. Catal. B Environ. 168-169 (2015) 559-571. doi:10.1016/j.apcatb.2015.01.019.

[60] M.A. Fontecha-Cámara, C. Moreno-Castilla, M.V. López-Ramón, M.A. Álvarez, Mixed iron oxides as Fenton catalysts for gallic acid removal from aqueous solutions, Appl. Catal. B Environ. 196 (2016) 207-215. doi:10.1016/j.apcatb.2016.05.032.

[61] P. V. Nidheesh, Heterogeneous Fenton catalysts for the abatement of organic pollutants from aqueous solution: A review, RSC Adv. 5 (2015) 40552-40577. doi:10.1039/c5ra02023a. 